\title{
A REVIEW OF CRITICAL INFRASTRUCTURE PROTECTION APPROACHES: IMPROVING SECURITY THROUGH RESPONSIVENESS TO THE DYNAMIC MODELLING LANDSCAPE
}

\author{
Uchenna D Ani ${ }^{*}$, Jeremy D McK. Watson' ${ }^{2}$ Jason R C Nurse ${ }^{3}$, Al Cook ${ }^{4}$, Carsten Maple \\ 1, 2 Department of Science Technology Engineering and Public Policy, University College London, United \\ Kingdom, \\ ${ }^{3}$ School of Computing, University of Kent, United Kingdom, \\ ${ }^{4}$ Critical Insights Security Ltd, United Kingdom, \\ ${ }^{5}$ Cybersecurity Centre, WMG, University of Warwick, United Kingdom \\ *u.ani@ucl.ac.uk
}

Keywords: critical infrastructure modelling, critical infrastructure protection, security modelling and simulation, IoT Modelling, CNI cybersecurity, cyber resilience modelling

\begin{abstract}
As new technologies such as the Internet of Things (IoT) are integrated into Critical National Infrastructures (CNI), new cybersecurity threats emerge that require specific security solutions. Approaches used for analysis include the modelling and simulation of critical infrastructure systems using attributes, functionalities, operations, and behaviours to support various security analysis viewpoints, recognising and appropriately managing associated security risks. With several critical infrastructure protection approaches available, the question of how to effectively model the complex behaviour of interconnected $\mathrm{CNI}$ elements and to configure their protection as a system-of-systems remains a challenge. Using a systematic review approach, existing critical infrastructure protection approaches (tools and techniques) are examined to determine their suitability given trends like IoT, and effective security modelling and analysis issues. It is found that empirical-based, agent-based, system dynamics-based, and network-based modelling are more commonly applied than economic-based and equation-based techniques, and empirical-based modelling is the most widely used. The energy and transportation critical infrastructure sectors reflect the most responsive sectors, and no one Critical Infrastructure Protection (CIP) approach - tool, technique, methodology or framework - provides a 'fit-for-all' capacity for all-round attribute modelling and simulation of security risks. Typically, deciding factors for CIP choices to adopt are often dominated by trade-offs between 'complexity of use' and 'popularity of approach', as well as between 'specificity' and 'generality' of application in sectors. Improved security modelling is feasible via; appropriate tweaking of CIP approaches to include a wider scope of security risk management, functional responsiveness to interdependency, resilience and policy formulation requirements, and collaborative information sharing between public and private sectors.
\end{abstract}

\section{Introduction}

Critical infrastructure (CI) involves elements that are fundamental to the normal operations of the human society [1], an can be defined as referring to any asset, system or part thereof which is critical for the maintenance of vital societal functions, health, safety, security, economic or social wellbeing of people, and the disruption or destruction of which would have a very substantial impact as a result of the failure to maintain those functions [2]. Arguably, it may be viewed as a nation's economic "central nervous system" [3] - making it difficult for nations without a properly functional, or indeed with vulnerable CI to attain and sustain its national goals of social and economic progress and development. Examples of CIs include; Energy (electricity, oil, natural gas), Chemical, Industrial Control, Dams, Defence Industries, Emergency
Services, Financial Services, Food and Agriculture, Government facilities, Commercial Services, Health and Public Health, Transportation, (Railways, Roads, Highways, Aviation, Shipping and Ports), Water and Waste water, Information Technology and Telecommunication, Nuclear [2], [4], [5].

There are growing concerns and debates about the protection of these types of CI systems, especially, how to effectively protect them given their vital positions in social and economic developments. These concerns have been highlighted with the increased emphasis on improved efficiency, performance and productivity, and this implies that CIs now rarely exist or function in isolation. Rather, they are becoming more tightly coupled into a system of (inter)dependent infrastructures, and converging with information and communications technology (ICT) and the Internet [6], [7]. This creates a complex multi- 
system interconnectedness and interactions referred to as a system-of-systems $(\mathrm{SoS})[8]$.

The growing trend for convergence and multi-system interconnectedness in CIs is introducing several security issues that threaten normal economic and social functions. As new technologies such as the Internet of Things (IoT) get integrated into CNI, new security risks (threats, vulnerabilities and attacks) emerge that require specific security solutions [9]. The risks are particularly hard to identify, and handle given that the IoT has emerged from a range of disparate fields of study [10]. The benefits of CIs can be realised if they function properly and are not impaired. This requires CIs to be kept safe from harm, and secure from any disruptive or destructive compromise. Thus, it is crucial to protect CIs, especially in the light of the growing and evolving malignity. It is important to understand potential security risks and how to effectively manage them using effective protection tools and techniques.

In the above context, the objective of protection may be explored through understanding how the attributes and capabilities of existing CI protection (security) modelling approaches fit and respond to the dynamics introduced by the evolving critical infrastructure and attack ecosystems. With the increasing adoption of IoT, it is crucial to track and understand research and development directions and outcomes, together with policy and regulatory interventions, which can better support security for critical national infrastructure (CNI) systems. CNIs provide some national benefits including; supporting the attainment of a properly functioning social environment and economic markets, enhancing service security, enabling external market integrations, and allowing service recipients (consumers, clients, and users) to benefit from new and emerging technological developments [3]. As such, their safe and resilient operation is imperative and effectively protection is required. Modelling and simulation $(M \& S)$ provide a useful technique to help achieve this. In terms of CIs, M\&S provide focused methods for analysing the dynamics of CI components, evaluating the interdependency and cascading effects amongst infrastructures based on system interactions [7]. M\&S uses the attributes, functionalities, operations, and behaviours of CI sub-systems to support various security analysis viewpoints, recognising and appropriately managing associated security risks. With several critical infrastructure protection approaches available, the question of how to effectively model the complex behaviour of interconnected $\mathrm{CNI}$ elements and configure their protection as $(\mathrm{SoS})$ remains a challenge.

This study provides novel insights on the effectiveness of existing CIP approaches (tools, techniques and methodologies) to address IoT-centric security risks, in order to guide the selection, adoption and/or development of more tailored approaches. This can provide a usable reference critical infrastructure security system developers, researchers and users. This contribution is achieved via a systematic and analytical study of available CIP tools, techniques, methodologies and frameworks herein collectively referred to as 'CIP Approaches'. The extent of risk management coverage for CIP approaches and their security responsiveness to the dynamic modelling landscape are evaluated through investigating: (i) Common CIP modelling approaches, (ii) the industrial sectors most responsive to CIP modelling and simulations, (iii) the sub-stages of risk management mostly covered by existing CIP approaches, (iv) the extent to which resilience, (inter)dependency and policy formulation factors are considered in existing CIP Approaches.

The rest of the paper is outlined as follows: Section 2 presents the related work. Section 3 describes the methodology used in the research. Section 4 presents the results and discussion, while Section 5, concludes the article and outlines recommendations based on our research.

\section{Related Works}

There is also a growing recognition and acknowledgement that to effectively preserve operational continuity in CIs, resilience is a necessary protection objective to complement security capacities [11], [12]. Resilience can be defined as the capacity to prevent, adapt, withstand and recover swiftly from both intentional and unintentional attacks [4], [13]. There are publications [14], [15] which emphasise that the understanding, modelling, and simulation of CI attributes, functions, operations and behaviours can support security analysis, especially given dynamicity in trends and technological adoption. Prior works [16]-[19] that have explored CIP modelling and simulation approaches does not cover newer approaches, such as the Industrial Control System Cyber Defence Triage Process (ICS-CDTP) [20]. These works also fail to address emerging needs such as resilience and support for security policy updates/formulation in modern CIs. This study takes a step towards providing some answers to fill gaps in existing literature.

\section{Methodology}

To achieve our research objectives, a systematic review approach [21] was used to identify and select related and relevant literature sources. This review technique can guarantee the quality and reliability of selected articles [22].

\subsection{Literature Gathering}

Searches for relevant literature was conducted using the Web of Science (WoS) article database. WoS was chosen because of its reputation for supervised selection and inclusion of materials drawing from high-quality and high-impact indexing by humans, consistent and structured documentation, better accuracy of results, and reduced duplicates and false positives [23]. In addition, WoS is the preferred choice and standard employed by most organisations [24]. Results were restricted to peer-reviewed articles (journals, conferences, reports, books, etc.) in order to ensure quality and credibility of outcomes. Key search phrases used were: 'Critical Infrastructure Protection Tools', 'Critical Infrastructure Security Techniques', 'Critical Infrastructure Security Methodologies', and 'Critical Infrastructure Security Management Methods'. Figure 1 presents the literature gathering process-flow. 
Initial search rounds using the above terms yielded a total search result of 1171 articles (represented as $N$ ) that included duplicated articles. Exclusion filtering - represented as $e$-was done based on titles to identify articles related to critical infrastructure protection. Unrelated articles were discarded, and only one instance each of relevant articles was retained. 303 related articles were obtained from the process, which reflected the initial selection study sample; $n$.

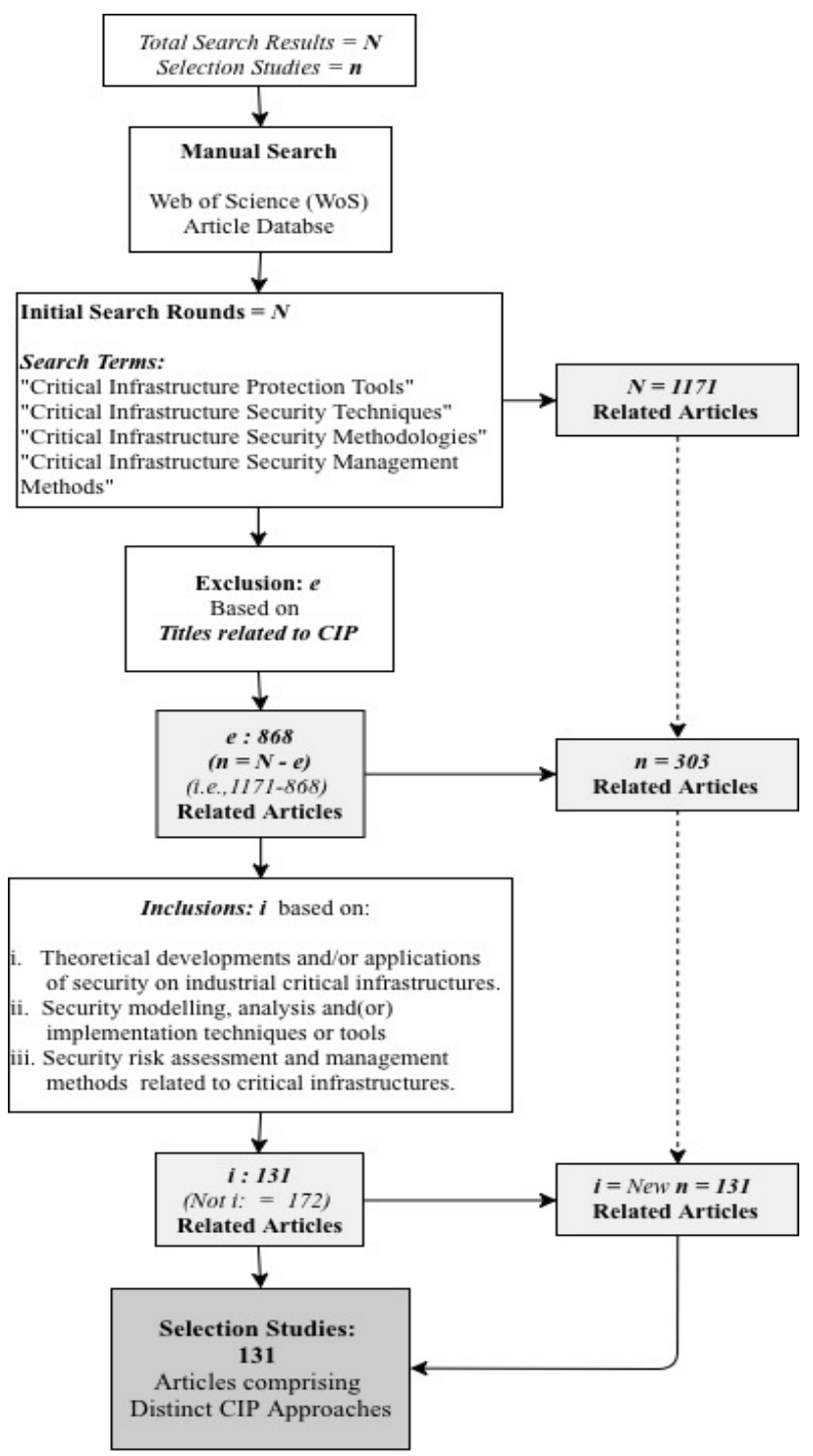

Figure 1: Literature Gathering Process

However, further inclusion filtering - represented as $i$; was performed to narrow the contextual scope and to select the most relevant articles that support the research objectives. These incudes:

i.) Articles on theoretical developments and(or) applications of security on industrial critical infrastructures.

ii.) Articles on security modelling, analysis and(or) implementation techniques or tools with use case applications in industrial critical infrastructure sectors. iii.) Articles on security risk assessment and management techniques/methods related to critical infrastructures.

\subsection{Literature Gathering Outcomes}

Based on the above criteria, 131 distinct CIP modelling, simulation, and/or implementation approaches characterising software tools, techniques, methodologies, and frameworks were compiled from journal and conference articles, reports, white paper, and guidelines. These are presented in Appendix A. These spanned from 1999 to 2017 and formed the final selection study sample (Figure 1).

\subsection{Evaluation Criteria}

The sample of the CIP approaches identified were evaluated based on criteria identified to be important for classifying CIP approaches. Most of which have been used in previous works. These criteria include; critical infrastructure types; applicable modelling technique; risk management sub-stages covered; and (inter)dependency and resilience modelling considerations.

Other criteria such as maturity and availability of CI tools were not used, although these have been used in the past [3] to evaluate CI tools. We think that there are uncertainties in accurately determining the maturity and availability status of some of the CIP tools given that they are mostly developed and used in-house, and as such this is an unreliable criterion to use. Reports and documentation on their use and effectiveness are not readily available in public domain. Similarly, whether they have been discarded, modified or upgraded, and at what point; is an information not easily available in the public domain. We think that adopting such criteria with potential for inaccurate data can greatly affect the accuracy of the overall study.

3.3.1 Critical Infrastructure Type: This is considered in order to highlight the varied levels of infrastructure criticality. In the UK, some CIs are categorised 'critical national infrastructures' - CNI, perhaps because of their huge contribution to the national economy. For example, the energy sector has an unrivalled value, a failure of which can cripple the functions of other CI sectors like emergency services, communications, health and transport, thus threatening national economy, social and political order [25].

3.3.2 Modelling Technique: This is considered because it connotes foundational representation of how each protection methodology is designed and applied. Although, CIP methodologies and techniques suggest varied modelling and simulation paradigms, and purpose-driven decision-making processes, they share a common goal exploring how to manage security risks. CIP modelling techniques may be classified into; agent-based, system dynamics, empirical, network, economic, and other (equation-based, real-time simulation, and cellular automata) techniques [26]. These may also be combined with additional computational methods such as discrete time-step, continuous time-step, Monte Carlo, decision-trees, geographical information systems, event monitoring, and risk management [3].

3.3.3 Risk Management: This context is considered because it provides a useful way of evaluating and responding to security 
issues in critical national infrastructure contexts [3], [16], [27], [28]. Most critical infrastructure protection implementations are typically based on risk management frameworks conceived as national or global standards [3]. Risk management approaches often vary either by; the nature of approach, or by how risk is measured [29], [30].

In this study, the 'nature of approach' is considered (nature of approach) - emphasising the criticality of assets, the potential harm that can be done to them, and the rippling interdependency effects that can affect other connected assets on the criticality chain. Thus, supported risk management substages in each CIP approach are analysed based on the National Infrastructure Protection Plan (NIPP) Critical Infrastructure Risk Management framework (RMF) [4] to underscore the purpose served by each. NIPP-RMF provides the most commonly supported guidelines in security objectives, strategies, and sector coverage. It also provides reference points to a broader community of nation states and infrastructure sectors exploring the development of tailored infrastructure security methodologies, tools and techniques [4].

NIPP-RMF suggests that risk management tools, techniques, and methodologies for CNI protection can be classified according to the purpose they serve, demonstrated by the substage(s) (Figure 2) of the overall CI risk management framework that is (are) supported, while applying each approach, and the associated outputs [4]. In the framework, CI elements can be physical, cyber and human. The framework also includes a process of recurrent information sharing and feedback into subsequent risk management sub-stages. Aside from the initial sub-stage of 'setting security goals and objectives', the key sub-stages of the framework used as evaluation criteria are: (i) identification of infrastructure assets, (ii) assessment and analysis of risks, (iii) risk management implementation (involving risk prioritisation, and risk control) and (iv) measurement of effectiveness.

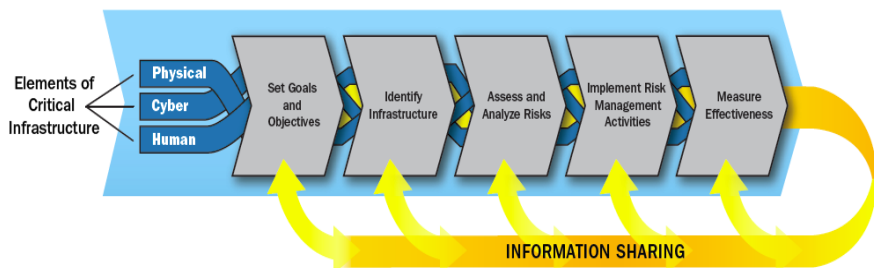

Figure 2: Revised NIPP Critical Infrastructure Risk Management Framework [4]

3.3.4 Interdependency and Resilience: Interdependency is a condition created by direct and/or indirect interconnectedness of CIs via geographically-distributed networks and physical hardware-based channels [8]. A disruption event can then spread consequences across channels of CIs, and society technically called 'cascading effects' [31], [32]. The harm from compromises can be physical, digital, economic, psychological, reputational, social and societal [33]-[35]. Since impact-flows across CI are as probable as the actual cyber-attacks themselves, it is crucial to understand the risks via modelling and simulations, in order to provide effective protection. Indeed, identifying and characterising interdependencies and complexities associated to CIs can improve the understanding of CIs as a SoS [36]-[38]. The insights that may be gained from failure and impact modelling and simulations can support the design of effective controls and response strategies [39].

Resilience describes a capacity to stop, cope with, acclimatize to, and/or recuperate from incidents that have negative consequences [4], [12]. With resilience in CIs, infrastructure functions, operations and services are reasonably maintained even in the face of an infrastructure disruption or compromise [33]. With attacks that cause cascades and failures, impacts can be economically and socially massive, so the need to be wellequipped to withstand and recuperate from adverse events is ever more necessary. Quite often, CI incidents happen unexpectedly, and complete control is rarely feasible. The dynamic threats and hazards landscape is such that it is hardly possible to foresee, prevent, prepare for, or control all CI security incidents, which in most cases can be unknown or emergent [33]. This necessitates a shift from the usual crisis management to resilience management to address supply chain disruptions and rapid restoration.

Appropriate readiness and recovery requires strengthening and investing in resilience to minimise sub-system vulnerabilities to restrict occurrence, intensity and propagation of failures and impacts on CIs and in turn on society [12]. It is appropriate that 'resilience' is becoming fundamental in general crisis and disaster management discourse, and is the focus of widespread efforts for resisting, absorbing, accommodating and recovering from the effects of security threats. This emphasises effort on preventive, mitigative and preparedness activities prior to a CI security crisis, response during the crisis, and the recovery after the crisis [13]. Integral dependencies and failure cascades should be considered in analysing and designing for resilience, and they should underscore the whole cycle of a CI security crisis, since it is impractical to guard against all threats [40], [41].

\section{Results and Discussions}

CIP approaches were analysed based on obtained information obtained about them from bibliographic literatures: reports, articles, white papers and guideline to arrive at informed insights. The list of approaches in Appendix A reflects a wide range of research being conducted in the area of critical infrastructure protection and considered relevant in the light of keeping pace with new trends like the IoT. The results of evaluating 131 CIP modelling approaches are thus presented.

\subsection{Results}

\subsubsection{Common modelling techniques applied in the CIP approaches}

For modelling techniques, we find that a variety of techniques are in use as shown in Figure 3. Empirical-based modelling appears to attract the widest application with $36(27.3 \%)$ of reviewed approaches in its favour. Examples of approaches in this category include: HURT, FTA, RVA, and RMCIS. Network-based modelling is seen in $32(24.2 \%)$ approaches 
including CASCADE, IRRIIS, and HAZOP. System dynamics-based modelling is used in 20 (about 15.2\%) approaches including AIMSUN, CIPMA, and ICS-CDTP. Agent-based modelling is applied in $26(19.7 \%)$ approaches including, CIMS, ADVISE, N-ABLE and GoRAF. Some CIP approaches combine two or more techniques. For example, $A C T$ combines economy-based and system dynamics-based modelling, while ADVISE and GoRAF both combine agentbased and real-time simulation techniques.

\subsubsection{Industrial sectors most responsive to CIP modelling and simulations}

Results of sector-based classification shown in Figure 4 indicates that $72(54.5 \%)$ CIP approaches applied to energy comprising electricity, pipeline \& oil, natural gas sectors. 42 (37.1\%) CIP approaches applied to the transportation sector. Water \& Waste Water has 47 (35.6\%) and Chemical sector has $41(31.1 \%)$ among others. Emergency Services has the least with $13(9.8 \%)$ applicable CIP approaches.

From a multi-sector applications viewpoint, 111 (84.1\%) of the CIP approaches mainly cover up to 5 sectors (1-5 sectors). 60 out of the 111 provide software support for engaging and implementing their designed operational processes. Only 4 (3\%) of the CIP approaches mainly cover between 6 to 10 sectors. These include: IIM, Risk Map, RVA, and BLDMP. Of the CIP approaches. $16(12.1 \%)$, cover at least $11 \mathrm{CI}$ sectors including; Athena, BIRR, CASCADE, CIDA, CIMSuite, CIPDSS-DM, EURACOM, Fort Future, IRRIS, ACT and ICSCDTP.

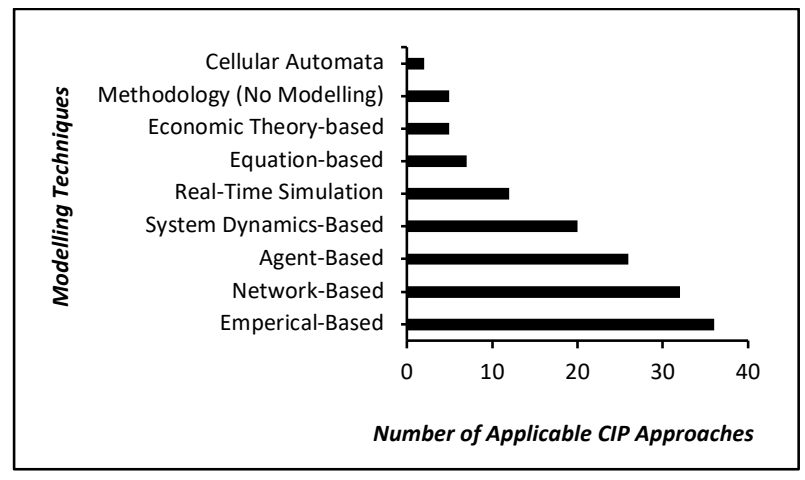

Figure 3: Modelling Techniques

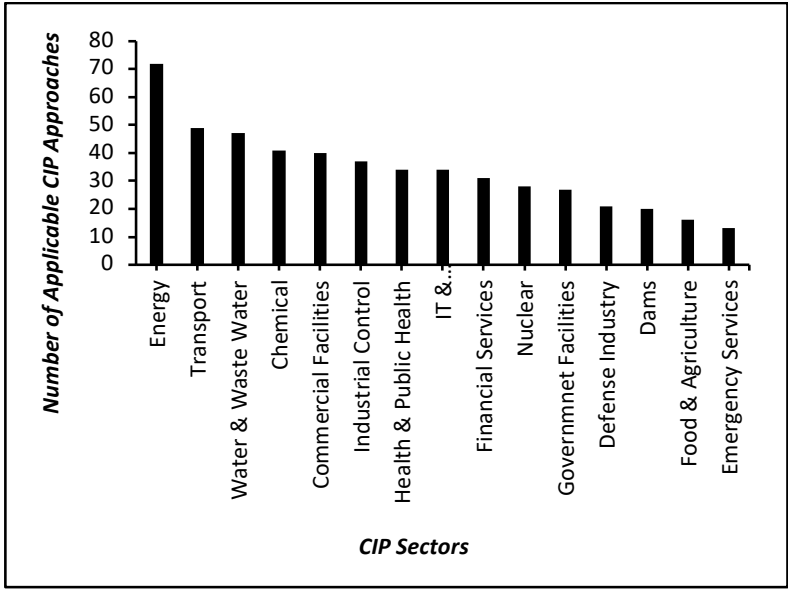

Figure 4: Sector-based Analysis of Occurrence of Critical Infrastructure Modelling and Protection Approaches

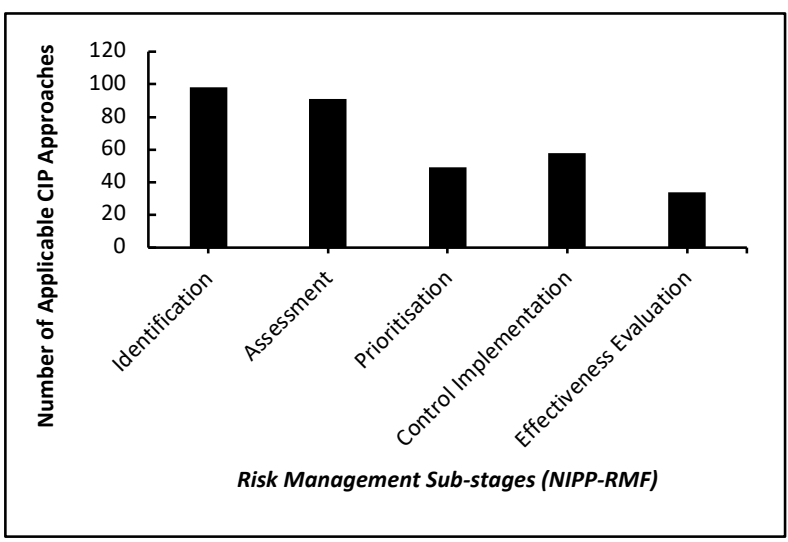

Figure 5: Risk Management Stages Covered

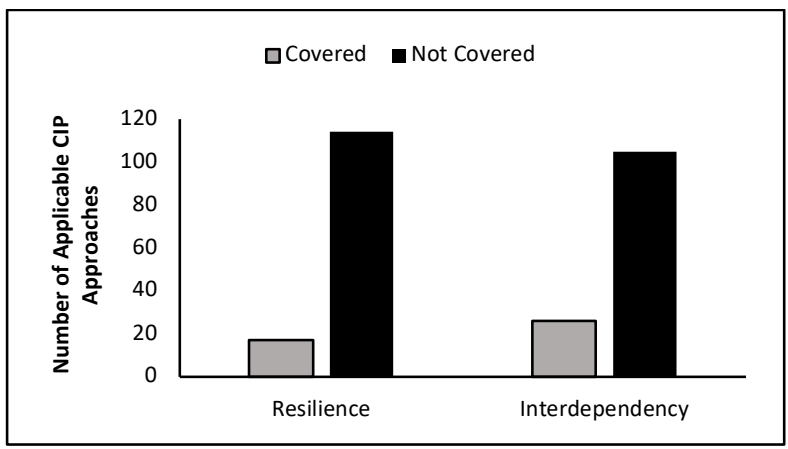

Figure 6: Analysis of Interdependency and Resilience Characteristics

4.1.3 Risk management sub-stages covered

98 (74\%) CIP approaches (Figure 5) included aspects related to 'identification of critical infrastructures and vulnerabilities' sub-stage. 91 (68\%) CIP approaches considered the 'assessment of risks' sub-stage. 82 (62\%) CIP approach considered some sort of 'risk management implementation', which is a sub-stage comprising 'risk prioritisation' and 'risk control' based on the Revised NIPP Critical Infrastructure Risk Management framework [4]. From these, 20 (nearly 24\%) approaches considered 'risk prioritisation' alone without 'control implementations', while 29 (nearly 35\%) approaches considered 'risk control implementation' alone without any form of prioritisation. 34 (nearly 26\%) CIP approaches 
considered 'effectiveness evaluation' sub-stage of the revised NIPP-RMF

Looking at the risk management implementation sub-stages (prioritisation and control) in isolation, more CIP approaches (58) i.e., 44\% of 131 characterised a sort of risk control implementation than risk prioritisation which had 49 CIP approaches. The 58 tools also represent $54 \%$ of the CIP approaches categorised under the risk implementation stage. Only half (29) approaches considered both risk prioritisation and control implementation stages, the remaining half considered just one of the two stages. In addition, fewer approaches consider all five sub-stages exclusively. $49 \%$ of the CIP approaches considered only two sub-stages, which most typically include: risk identification and risk assessment. Only $6(4.5 \%)$ of CIP approaches considered all five sub-stages. These include: BIRR, COUNTERACT, EURACOM, IRRIIS, $N S R A M$, and NIPP-RMF itself. This latter category of approaches exists as broad guiding frameworks (NIPP-RMF) or methodologies (BIRR, COUNTERACT, EURACOM, IRRIIS) or a complex modelling tool with software support $(N S R A M)$. The methodologies and framework are mostly applicable to a generality of CI sectors, while the software modelling tool NSRAM is applicable for chemical, energy and IT/Communications sectors.

\subsubsection{Interdependency and Resilience considerations}

Only 28 , or $21 \%$, of reviewed approaches considered elements of interdependency modelling (Figure 6). Examples of approaches with explicit characterisation of interdependencies include: AIMS, Athena, CASCADE, CIPMA, CISIA, N-ABLE, $N E M O$, and UIS. We assume these considerations of interdependency phenomena may be connected to the core objectives for developing the tools in the first place. This may be influenced by an acknowledgement of criticality of interdependencies for both constructive and destructive impacts on CI operations. Behavioural and cascading effects of functions and failures appear to be at the core of the objectives for developing most of the listed approaches in this group.

For resilience coverage, only 18 (14\%) out of the 131 CIP approaches clearly considered aspects related to resilience modelling (Figure 6). Examples in this category include: BIRR, CIMS, CIPMA, DECRIS, EURACOM, Fort Future, IIM, MBRA, HAZOP, Risk Maps, RAMCAP-Plus, Sandia Risk Assessment Methodology, NIPP-RMF, and RMCIS. Potential reasons why a greater proportion of CIP approaches do not consider resilience attributes may relate to: (i) the core objectives of their developments, which points to perceived requirements for protecting critical infrastructures. Resilience may not have been part of the requirements for development. (ii) the development time for the CIP approaches, which may have predated the concept of resilience in critical infrastructures - CI resilience may not have been clearly defined and/or gained wide attention. Thus, it is assumed that the CIP approaches that have considered resilience may have emerged as responses to newer challenges associated with convergence and hyper-connectivity trends, which have made resilience a necessary objective. Only 4 (3.1\%) CIP approaches considered both resilience and (inter)dependency modelling attributes, as well as policy and regulatory formulation attributes.

\subsection{Discussion of Findings}

On a general base, a huge proportion of the sample of CIP approaches exist as either tools, techniques or methodological frameworks. The approaches seem mostly structured to handle operations and performance modelling and simulations, rather than security. However, they can also be used for securityrelated attributes such as evaluating the impact of security features or their absence with critical infrastructures. In addition, it is not clear how much of IoT performance and security are reflected in the reviewed CIP approaches. This may be because most of the approaches predate the IoT trend. A common characteristic shared by these the various CIP approaches is that they are all based on risk management, although they are distinguishable by the scope or sub-stage of overall security risk management functions considered in each approach.

We find that the common modelling techniques which receive widespread interest and adoption include: agent-based, system dynamics-based, network-based and empirical-based. These are not the only applicable techniques but only represent the most commonly used, and a quite applicable for IoT contexts too. Newer techniques may be defined from combining two or more of the above, or even entirely new modelling paradigms depending on intended development goals. The aim being to enable a multi-level modelling and simulation to meet the various requirements that may be set by IoT.

At the moment, the empirical-based model seems to be most widely employed for CIP research and the development of security approaches. This is closely followed by networkbased and system dynamics-based modelling techniques. These preferences could link to growing data-driven technology trends and reflect an increasing need to understand and evaluate CI security using real or actual historic data and drawing from expert knowledge and experiences.

For IoT-based critical infrastructures, this is good news, because IoT systems typically characterise huge volume of data from sensors connected to CI components. Empirical modelling can enable a simulation system involving the collection and dissemination of such sensor-acquired CI data and their management via a context-aware data distribution service to be used by application [42]. Potential applications include smart cloud services that can take and integrate such data with other available data (crowd-sourced or crowdsensed) to support real and high-fidelity analysis and insights. Although this will typically come with a lot of complexities networks, communications and pervasiveness that needing resolve during the modelling process. By combining sensed and historic data, it becomes easier to observe and connect the interrelationships and interdependencies among critical infrastructure components, system and sectors. Thus, empirical-based modelling techniques seem to better support the identification of more recurrent, realistic and suggestive 
failure patterns, quantifying interdependency-related indicators for risk mitigations, supporting emergency decision-making and providing validation parameters to support other modelling techniques [26].

Agent-based modelling is also very applicable for IoT as 'things' in critical infrastructures can be considered as agents that interact with other agents to enable a seamless operation. Network-based modelling provides an ability to model interdependencies among IoT-based CI systems, especially within localised areas. The technique simplifies the derivation of insights related to CI representations along topological or flow-pattern analysis line, and the evaluation of cascading impacts. As the emphasis on fidelity, dependency and resilience of CIs increases, interests and support may move towards empirical-based modelling, with progressive support for network-based, agent-based, and system dynamics-based modelling. The lesser emphasis on other modelling techniques (such as equation-based, economy-based, etc.) may indicate a lack of popularity for their concepts perhaps due to a greater complexity in their use.

Although modelling and simulation are applicable to several industrial CI sectors, the widest or highest sensitivities seem to come from the energy sector. This sector comprises electricity, pipeline and oil, and natural gas CIs. Transportation, water \& waste water, and chemical industries also have significant interest and responsiveness. These sectors all fall within the category of CNIs defined in the UK CPNI documentation [5]. The energy sector is critical because several other critical infrastructures depend on its products/services. Nearly all other CIs require some form of energy source (from an energy sub-sector) to drive their functionalities. Thus, the energy sector takes on an almost indispensable position within critical infrastructure interdependencies. The consequences and impact of energy infrastructure failure can inevitably ripple through and affect other dependent infrastructures. If unattended to, the effects can cause a myriad of damaging cascading outcomes (physically, operationally, and economically) in the chain of interdependent CIs within a national or global social ecosystem. This can explain the greater concerns and sensitivities concerning a more secure and continuously improving energy sector, as opposed to the lesser emphasis in other CIs.

Although the IoT promises huge benefits for CIs like energy and transport, it also brings new and complex issues. IoT poised to improve energy and transport efficiencies, reliability, proactive maintenance, and utilisation visibilities amongst other. But there are issues of security, interoperability, scalability and logistics needing to be address. Modelling provides ways of learning the scales on both perspectives, and how they might be addressed.

Emergency services, food \&. agriculture, dams appear to demonstrate low interests and responsiveness to CIP modelling and simulations. This could be because these sectors often appear at the tail of CI interdependency chains, and typically have low direct and immediate large-scale social consequences and impacts when compromised. In addition, responses in form of solutions are typically responsive to, and trail similar paths as the direction of growing malicious events. Moreover, these sectors appear not to be suffering increasing cyber-attacks judging by known recorded incidents [43]. While it may be rational to focus solutions where there are greater threats and risk challenges, the potentials for common cause failures are very imminent, hence, it is crucial to also give a good measure of attention other CI sectors.

Clearly, empirical-based, network-based, and agent-based modelling techniques are the three most widely used techniques in fulfilling the risk management framework substages. System-dynamics-based techniques are typically used for simulating continuous system behaviours such as estimating the effectiveness of implemented procedures in critical infrastructures. Observed consistent patterns suggest that empirical-based modelling is more widely employed in risk identification, assessment, prioritisation and control implementations sub-stages, and less consideration for effectiveness evaluations sub-stage. Network-based modelling is widely adopted for risk identification, assessment and control implementation. We assume this is so because network-based techniques (either topology-based or flowbased methods) are helpful in capturing interdependency characteristics, CIs descriptions, and identifying the critical components with suggestions for emergency protection and response improvements [26]. As IoT continue to find its way into CIs, concerns about how to learn their impact on host components and interdependencies are likely to influence the use of network-based modelling techniques.

In general, results suggest a greater interest on CI researches around risk identification, assessment, and control implementation in that order. Traits of risk prioritisation and effectiveness evaluation do not seem to enjoy much attention and research. Thus, the aspects of security risk management with the most interests and presumed relevance, as well as where the direction of CIP developments tends can be easily seen. It reveals that beside identifying and assessing security risks on CIs, the next thought in the minds of CI owners and operators is what controls to implement to mitigate or eliminate characterised risks. This indicates that thinking about implementing controls may be viewed as more important than first understanding the varied criticality levels of security risks before conceiving a strategy for implementing controls to yield the highest possible security and resilience outcomes. These thoughts need to start shifting towards the new risk status that relate to IoT-in-CIs; from identification to effectiveness evaluations. New thought directions for modern CIs (now with IoT) risk management need to extend to the less appreciated significance of assessing the extent to which desired CIP has been achieved post control implementation to obtain success measures and potential guides for further improvements. Common issues and debate seems to pivot around the variability of approaches for measuring risks, and how such measures are reflective of true system states also need to address IoT issues. 
Quite a few (less than one-fifth) of the CIP approaches considered resilience. Greater focus and purpose-driven developments tended towards defending malicious attacks or compromises on CIs. Contexts that can help reduce attack impacts and sustain operations or functionalities during and after successful compromises did not enjoy wide consideration. This could be because most CIP approaches were evolved before the trend of 'resilience' - implying they were already in use prior to when resilience became a feature of significance and concern, and newer/updated versions of these approaches are yet unavailable. Alternatively, the significance of ensuring resilience may also not have been clearly understood by developers as at the time of developing some of the approaches - making for why resilience feature is not reflected in the tools. Besides implementing preventive security, the need to ensure a capacity to continue operations - delivering the needed services while managing attacks - is ever more important. Clearly, for CNI sectors, disruptions or their cascading effects are not welcomed phenomena. Anticipation, prevention, absorption, adaptation and rapid recovery are essential towards achieving resilience. While newer CIP approaches benefit from resilience features, older approaches need to be modified to embody resilience where missing. As an example, we consider the NIPP-RMF that lacked resilience in its maiden version but was later revised in 2013 to include both security risk and resilience characteristics.

Although not having widespread acceptance and inclusion, (inter)dependency coverage seems more prevalent than resilience in the CIP approaches. The modelling dimensions covered include: Component/infrastructure-level (e.g., AIMS, MUNICIPAL), operational/functional-level (e.g., CASCADE, CIPMA), vulnerability-level (e.g., MIA), Cost/Time-dependencies (e.g., CI3), and market effects (e.g., CommAspen). Results reveal a growing appreciation of the significance of interdependencies in CIP modelling and analysis. Private and public $\mathrm{CI}$ owners and operators are beginning to recognise that learning the relationships amongst CI components and systems can greatly support the attainment and enhancement of security and resilience.

Again, the few approaches mostly emerge from research institutes and academic institutions rather than government regulatory agencies. Current outlook also suggests that the domain of CIP is more characterised with self-garnered defensive solutions rather than being compliance-based mediums. This individuality and the differences in security problems and requirements can be the drivers for the development and adoption of bespoke protection techniques by infrastructure organisations.

From a multi-attribute consideration viewpoint, very few CIP approaches currently consider the combined attributes of interdependency and resilience. For example, out of 131 approaches reviewed, only CIMS, CIPMA, and IIM appear to satisfy the above criteria. Interestingly, none of these approaches applied the more common empirical or networkbased modelling techniques. Rather, these use agent-based and system dynamics modelling. This reveals the limitations of existing CIP approaches to sufficiently address the security dynamics in modern CIs. The level of multi-attribute coverage appears to be significantly low compared to the proportion of CIP approaches being developed, further suggesting a crucial need to upgrade or refine existing approaches to address any attribute deficiencies in order to improve their effectiveness.

\section{Conclusion and Recommendations}

Arguably, modelling for critical infrastructure protection seems not entirely new, as its underlying concepts typically relate to safety modelling and analysis. Only that over time, has security become relevant and emphasised due to technology trends. This has made CI sectors readily susceptible to intentional cyber-engineered attacks. Having also become so tightly coupled and interdependent, incidents show that the compromise, disruption and failure of CIs is not only restricted to causes and vectors related to natural disasters. Human-initiated actions via technology abuse or mal-interventions can be and increasingly are, an influence.

However, what seems new and perhaps not well reflected - at least directly in most of the critical infrastructure modelling and security approaches (tools, techniques, and methodologies) - is the concept of addressing 'resilience'. Most CIP approaches reviewed mainly focus on exploring concepts and phenomena related to security, reliability, dependability and risks in CIs. We reckon that a plausible reason for this may be linked to the early and more widespread emphasis on these attributes. Also, it may be attributed to the ease in defining and evaluating the above attributes compared to evaluating resilience. For example, studies [44] indicate a common acknowledgement by power company executives about a better comparative convenience for the ease of defining and measuring of CI reliability than CI resilience. Be this as it may, this apparently intractable attribute is now hihgly relevant to meeting the evolving protection needs of CI sectors.

The typical contexts that characterise the objectives for developing CIP modelling approaches - either tools, techniques or methodologies; emphasise the desire to understand the dynamic behaviours of CI systems using modelling techniques such as agent-based, system dynamicsbased, network-based, and empirical-based techniques. These techniques help to identify and characterise the causes of functional/operational anomalies and/or disruptions within CI setups through determining critical hazards and risks, their interdependencies, consequences and impact cascades. CIP should embrace modelling and analysis of security-related operations, activities and risk management, mostly within the confines of specific infrastructure environments and sectors.

In relations to how CIP is modelled, security risk management methods drive the process for gaining deeper security-related performance insights for CIs to support effective responses. Wider interests focus more on the starting sub-stages of risk management including: (i) identification of Critical infrastructure, hazards and vulnerabilities, and (ii) assessment and analysis, of security risks. Empirical-based modelling 
combined with risk identification, assessment, implementation and management of risk are among the most common implementation modes. These seem influenced by the growing adoption of setups and models that generate or feed-on actual scenario data to support CIP sensitivity analysis for decisionmaking.

The energy and transportation sectors demonstrate the widest concerns and efforts on protecting CNIs. This is not surprising as these sectors have higher criticalities and provide services that sustain several other sectors. Less sensitive sectors like emergency services, food and agriculture and dams need to emulate the drives and actions of the energy and transportation sectors, to ensure that they are well-equipped to handle security threats when they eventually surface. In balancing the trade-off between 'specificity' and 'generality', their key individual benefits need to be considered. Specificity allows for more focused context coverage and analysis, which can mean better and more tailored solutions, which will mean better and more tailored solutions. Conversely, generality enables a tool to be applicable to multiple CI sectors. However, a single approach - a tool or technique - cannot support holistic security modelling of CIs. A combination of multiple approaches - preferably integrated into a tool and technique (methodology or framework) - is perhaps the way to go. In addition, an approach that includes the pragmatics of implementing necessary control actions to curb security risks, as well as learning the effectiveness of controls can be a preferred solution.

Resilience modelling links to interdependency, and interdependency analysis contributes information and insights about the degree of cross-systems impact inducible by failures or disruptions. It also contributes to the perception on the level of resilience achievable in principle and practice. While some of the CIP approaches acknowledge and consider dependency or cross-dependency relationships and attributes, a larger proportion either implicitly include it or utterly overlook it. In this era of IoT, advancing technology convergence and system hyper-connectivity, understanding the interdependencies amongst CI components and systems can strongly make the difference between ignorance and knowledge on the nature, type, and degree of resilience required to enhance protection of CIs.

A significant number of the CIP approaches reviewed emerge as instruments developed by government agencies responsible for protecting CIs, or by research laboratories, for example the Idaho National Laboratory in the USA (who are also funded by the government. This could present an effective way for government and regulators to encourage a wider use of CIP approaches. However, the extent to which governmentsponsored approaches are realistically adopted in the private sectors is often unclear or in doubt, since this latter group run substantial chunks of CI systems. We posit that policies that support easy adoption of approaches are necessary in the above regard. Also, the private sector shows mixed responses to seamless monitoring and reporting of cybersecurity vulnerabilities and incidents. Even in cases where shared information, cooperation and assistance can significantly support realising acceptable protection of CIs from threats and attacks, decisions and actions are often determined by growing pressures for business competitive advantage [45]. Policies that advance and manage shared and collaborative information capability between public (government) and private sector stakeholders would be very helpful in this regard.

Clearly, security risks for CIs are evolving along new technology pathways where IoT devices and applications are finding their ways into CI systems. IoT systems are commonly characterised by; variability of scale in components, temporality of connections amongst devices, and the heterogeneity of actors. These characteristics influence conditions that can exist between periodic risk assessments without necessarily reporting on instantaneous risk impacts to the whole system. Since the risk assessment mode in existing CIP approaches are designed to operate statically periodically, they lack appropriate capabilities to address the dynamics and transient threats in IoT [30], [46], agree that dynamic risk assessment has become necessary. Such dynamic assessment mode would need to address this looming problem by catering for emerging system connectivity in real-time, as well as characterising, in clear and timely way, the level of temporality of devices in relations to their risk impacts.

Thus, to ensure effective; CIP modelling and simulations, sensitivity to dynamic trends, and potentially sustainable and efficient 'Living in the IoT', this study recommends that,

i. Other security conscious but less-responsive critical infrastructure sectors such as emergency services, food \& agriculture, and dams; should draw lessons from the efforts of the energy and transportation sectors. Analogous approaches should increase the ability to evaluate and understand security risks to attendant infrastructures and operations. They can support better understanding of any associated dependencies and cascading impacts and improve understanding of how to establish effective security and resilience. The decisionmaking processes related to measuring the effectiveness of readiness activities and investments will be improved, as well as the behavioural responses to CI disturbances or disruptions in the sectors.

ii. Newer or updated CIP modelling approaches should be developed or revised to capture scope of IoT in security risk management - from identification to effectiveness evaluations. This is to support appropriate alignments and responsiveness to the evolving trends introduced by new technologies such as IoT and IIoT. Such approaches also need to adopt dynamic and real-time assessment processes to address the issues introduced by IoT in CIs, and the high impact security risks that emerge.

iii. A strong public-private sector partnership is important and should be vigorously pursued by both stakeholder groups to achieve better security and resilience in CIs. Such collaboration can empower the public sector to monitor, in timely and efficiently ways, and to aggregate information about CI security threats, vulnerabilities, 
incidents and impacts as they emerge. The public sector can also provide the risk information to private sector operators to help them ensure an informed and wellorganised security management.

\section{Acknowledgements}

The Research leading to the results presented in this paper comes from the Analytical Lenses for Internet of Things (ALIoTT) project under the PETRAS Cybersecurity of the Internet of Things Research Hub. It has received funding from The Engineering and Physical Sciences Research Council (EPSRC).

\section{References}

[1] G. Pescaroli and D. Alexander, "Critical infrastructure, panarchies and the vulnerability paths of cascading disasters," Nat. Hazards, vol. 82, no. 1, pp. 175-192, 2016.

[2] The Council of the European Union, "Council Directive 2008/114/EC of 8 December 2008 on the indentification and designation of European critical infrastructures and the assessment of the need to improve their protection," Off. $J$. Eur. Union, pp. 75-82, 2008.

[3] J. M. Yusta, G. J. Correa, and R. Lacal-Arántegui, "Methodologies and applications for critical infrastructure protection: State-of-the-art," Energy Policy, vol. 39, no. 10, pp. 6100-6119, 2011.

[4] Department of Homeland Security, "NIPP 2013: Partnering for Critical Infrastructure Security and Resilience," 2013

[5] CPNI, "Critical National Infrastructure | CPNI | Public Website," CPNI, 2018. [Online]. Available:

https://www.cpni.gov.uk/critical-national-infrastructure-0. [Accessed: 03-Apr-2018].

[6] A. Laugé, J. Hernantes, and J. M. Sarriegi, "Critical infrastructure dependencies: A holistic, dynamic and quantitative approach," Int. J. Crit. Infrastruct. Prot., vol. 8, pp. 16-23, 2015.

[7] G. Oliva, S. Panzieri, and R. Setola, "Modeling and simulation of critical infrastructures," WIT Trans. State Art Sci. Eng., vol. 54, pp. 39-56, 2012.

[8] G. Amélie, B. Aurélia, and L. Emmanuel, "The Challenge of Critical Infrastructure Dependency Modelling and Simulation for Emergency Management and Decision Making by the Civil Security Authorities.," in Critical Information Infrastructures Security. CRITIS 2015. Lecture Notes in Computer Science, vol. 9578, E. Rome, M. Theocharidou, and S. Wolthusen, Eds. Cham: Springer Cham, 2016, pp. 255-258.

[9] C. Alcaraz and S. Zeadally, "Critical infrastructure protection: Requirements and challenges for the $21 \mathrm{st}$ century," Int. J. Crit. Infrastruct. Prot., vol. 8, pp. 53-66, 2015.

[10] C. Maple, "Security and privacy in the internet of things," J. Cyber Policy, vol. 2, no. 2, pp. 155-184, 2017.

[11] National Infrastructure Advisory Council., "Critical Infrastructure Resilience Final Report and Recommendations." U.S. Department of Homeland Security, Washington, DC, USA, pp. 1-54, 2009.

[12] D. Rehak, P. Senovsky, and S. Slivkova, "Resilience of Critical Infrastructure Elements and Its Main Factors," Systems, vol. 6, no. 2, p. 21, 2018.

[13] C. Pursiainen, "Critical infrastructure resilience: A Nordic model in the making?," Int. J. Disaster Risk Reduct., vol. 27, no. 653390, pp. 632-641, 2018.
[14] W. Knowles, D. Prince, D. Hutchison, J. F. P. Disso, and K. Jones, "A survey of cyber security management in industrial control systems," Int. J. Crit. Infrastruct. Prot., vol. 9, pp. 52-80, 2015.

[15] Y. Ashibani and Q. H. Mahmoud, "Cyber physical systems security: Analysis, challenges and solutions," Comput. Secur., vol. 68, pp. 81-97, 2017.

[16] Y. Cherdantseva et al., "A review of cyber security risk assessment methods for SCADA systems," Comput. Secur., vol. 56, pp. 1-27, 2016.

[17] G. Giannopoulos, R. Filippini, and M. Schimmer, "Risk assessment methodologies for Critical Infrastructure Protection. Part I: A state of the art.," European Union, Luxembourg, 2012.

[18] E. Wiseman, "Critical Infrastructure Protection and Resilience Literature Survey: Modeling and Simulation," Ottawa, Canada, 2014.

[19] G. Stergiopoulos, E. Vasilellis, G. Lykou, P. Kotzanikolaou, and D. Gritzalis, "Critical Infrastructure Protection Tools: Classification and Comparison," in Critical Infrastructure Protection X. ICCIP 2016. IFIP Advances in Information and Communication Technology, Vol 485., M. Rice and S. Shenoi, Eds. Springer Cham, 2016, pp. 1-25.

[20] A. Cook, H. Janicke, R. Smith, and L. Maglaras, "The industrial control system cyber defence triage process," Comput. Secur., vol. 70, pp. 467-481, 2017.

[21] M. J. Grant and A. Booth, "A typology of reviews: an analysis of 14 review types and associated methodologies," Health Info. Libr. J., vol. 26, pp. 91-108, 2009.

[22] D. Tranfield, D. Denyer, and P. Smart, "Towards a Methodology for Developing Evidence-Informed Management Knowledge by Means of Systematic Review," Br. J. Manag., vol. 14, no. 3, pp. 207-222, 2003.

[23] J. C. F. de Winter, A. A. Zadpoor, and D. Dodou, "The expansion of Google Scholar versus Web of Science: A longitudinal study," Scientometrics, vol. 98, no. 2, pp. 1547-1565, 2014.

[24] S. Kendall, "PubMed, Web of Science, or Google Scholar? A behind-the-scenes guide for life scientists," Research Guides, 2017. [Online]. Available: https://libguides.lib.msu.edu/c.php?g=96972\&p=627295. [Accessed: 04-Dec-2018].

[25] P. Sieńko, "Methods of securing and controlling critical infrastructure assets allocated in information and communications technology sector companies in leading," Securitologia, vol. 22, no. 2, pp. 107-123, 2015.

[26] M. Ouyang, "Review on modeling and simulation of interdependent critical infrastructure systems," Reliab. Eng. Syst. Saf., vol. 121, pp. 43-60, 2014.

[27] U. P. D. Ani, H. (Mary) He, and A. Tiwari, "Review of cybersecurity issues in industrial critical infrastructure: manufacturing in perspective," J. Cyber Secur. Technol., vol. 1, no. 1, pp. 32-74, 2017.

[28] K. Stouffer, V. Pillitteri, S. Lightman, M. Abrams, and A. Hahn, "Guide to Industrial Control Systems (ICS) Security - NIST.SP.800-82r2.” NIST, US Department of Commerce, Gaithersburg, Maryland, pp. 1-247, 2015.

[29] A. Shameli-Sendi, R. Aghababaei-Barzegar, and M. Cheriet, "Taxonomy of information security risk assessment (ISRA)," Comput. Secur., vol. 57, pp. 14-30, 2016.

[30] J. R. C. Nurse, S. Creese, and D. De Roure, "Security Risk Assessment in Internet of Things Systems," IT Prof., vol. 19, no. 5, pp. 20-26, 2017.

[31] P. Kotzanikolaou, M. Theoharidou, and D. Gritzalis, "Cascading Effects of Common-Cause Failures in Critical 
Infrastructures," in Critical Infrastructure Protection VII,

Series Vol., vol. 417, no. 2003, J. Butts and S. Shenoi, Eds. Berlin Heidelberg: Springer Berlin Heidelberg, 2013, pp. 171-182.

[32] A. Laugé, J. Hernantes, and J. M. Sarriegi, "Disaster impact assessment:A holistic framework," in ISCRAM 2013

Conference Proceedings - 10th International Conference on Information Systems for Crisis Response and Management, 2013, no. May, pp. 730-734.

[33] R. Setola, E. Luiijf, and M. Theocharidou, "Critical Infrastructures, Protection and Resilience," Springer Cham, 2016.

[34] Buncefield Major Incident Investigation Board (BMIIB), "The Buncefield Incident 11 December 2005, Volume 2," 2008.

[35] I. Agrafiotis, J. R. C. Nurse, M. Goldsmith, S. Creese, and D. Upton, "A taxonomy of cyber-harms: Defining the impacts of cyber-attacks and understanding how they propagate," J. Cybersecurity, vol. 0, no. 0, pp. 1-15, 2018.

[36] R. E. Bloomfield, P. Popov, K. Salako, V. Stankovic, and D. Wright, "Preliminary interdependency analysis: An approach to support critical-infrastructure risk-assessment," Reliab. Eng. Syst. Saf., vol. 167, no. March, pp. 198-217, 2017.

[37] P. Pederson, D. Dudenhoeffer, S. Hartley, and M. Permann, "Critical Infrastructure Interdependency Modeling: A Survey of U.S. and International Research," 2006.

[38] M. Schläpfer, T. Kessler, and W. Kröger, "Reliability Analysis of Electric Power Systems Using an Objectoriented Hybrid Modeling Approach." Cornell University Library, pp. 1-8, 2012.

[39] R. Bloomfield, L. Buzna, P. Popov, K. Salako, and D. Wright, Stochastic modelling of the effects of interdependencies between critical infrastructure, vol. 6027 LNCS. Springer Berlin Heidelberg, 2010.

[40] Australian Government, Critical Infrastructure Resilience Strategy, no. September 2001. Commonwealth of Australia, 2010.

[41] A. Alsubaie, K. Alutaibi, and J. Marti, "Resilience Assessment of Interdependent Critical Infrastructure," Crit. Inf. Infrastructures Secur. CRITIS 2015. Lect. Notes Comput. Sci., vol. 9578, pp. 43-55, 2016.

[42] A. Al-Fuqaha, M. Guizani, M. Mohammadi, M. Aledhari, and M. Ayyash, "Internet of Things: A Survey on Enabling Technologies, Application and Standardization," IEEE Commun. Surv. Tutor., vol. 17, no. 4, pp. 2347-2376, 2015.

[43] U. D. Ani, N. Daniel, F. Oladipo, and S. E. Adewumi, "Securing industrial control system environments: the missing piece," J. Cyber Secur. Technol., vol. 2, no. 3-4, pp. 131-163, 2018.

[44] A. R. Berkeley and M. Wallace, "A Framework for Establishing Critical Infrastructure Resilience Goals: Final Report and Recommendations," 2010.

[45] J. Perkins, J. Hyde, and A. Falconer, "Study on Risk Governance of European Critical Infrastructures in the ICT and Energy Sector," Oxfordshire, 2009.

[46] L. Atzori, A. Iera, and G. Morabito, "The Internet of Things: A survey," Comput. Networks, vol. 54, no. 15, pp. 2787-2805, 2010. 
To be published in PETRAS/IET Conference Living in the Internet of Things: Cybersecurity of the IoT - 2019 Appendix A: Selection Study Sample of Critical Infrastructure Protection Approaches

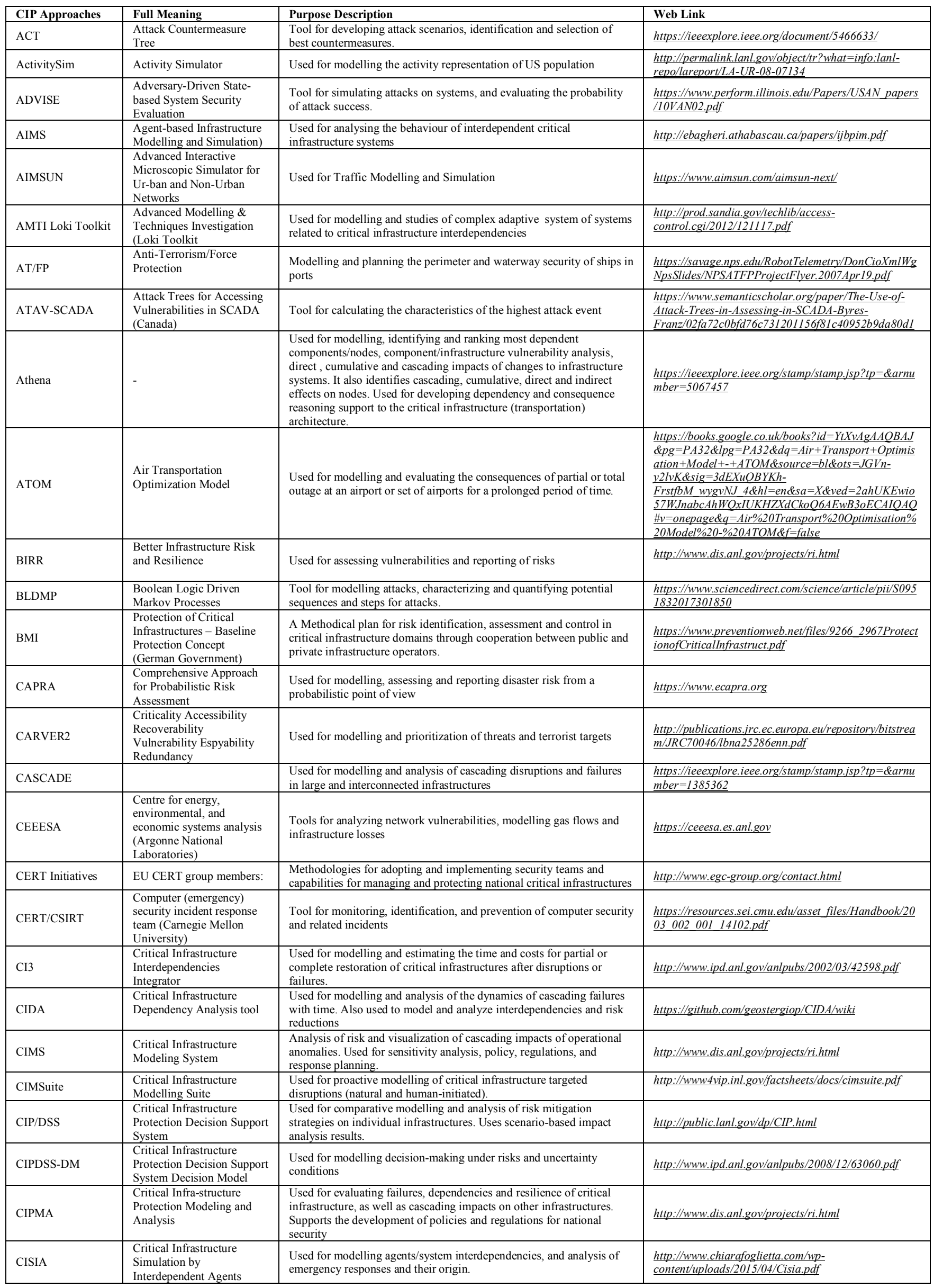


To be published in PETRAS/IET Conference Living in the Internet of Things: Cybersecurity of the IOT - 2019

\begin{tabular}{|c|c|c|c|}
\hline CIP Approaches & Full Meaning & Purpose Description & Web Link \\
\hline COMM-ASPEN & $\begin{array}{l}\text { Agent-based simulation } \\
\text { model of the US economy }\end{array}$ & $\begin{array}{l}\text { Used for modelling the effects of market decision and disruptions of } \\
\text { telecommunications infrastructure to the economy. }\end{array}$ & http://www.dis.anl.gov/projects/ri.html \\
\hline $\begin{array}{l}\text { CORAS-BRA- } \\
\text { SCADA }\end{array}$ & $\begin{array}{l}\text { CORAS-Based Risk } \\
\text { Assessment for SCADA } \\
\text { (USA). }\end{array}$ & $\begin{array}{l}\text { Tool for modelling the risks of ICS prototypes using the CORAS } \\
\text { framework }\end{array}$ & $\begin{array}{l}\text { https://pdfs.semanticscholar.org/3143/940955a76a496 } \\
\underline{46 \text { ba2954e0735a0ecl } 8 d 7 \text { ca.pdf }}\end{array}$ \\
\hline COUNTERACT & $\begin{array}{l}\text { Cluster of User Networks in } \\
\text { Transport and Energy } \\
\text { relating to Anti-terrorist } \\
\text { Activities }\end{array}$ & Used for risk assessment, mitigation and reporting & http://www.dis.anl.gov/projects/ri.html \\
\hline $\begin{array}{l}\text { CSASG-SCADA } \\
\text { Systems with Game } \\
\text { Models }\end{array}$ & $\begin{array}{l}\text { Cyber Security Analysis of } \\
\text { Smart Grid SCADA } \\
\text { Information Security (USA) }\end{array}$ & $\begin{array}{l}\text { Tool for identifying the best action strategy for attackers and defenders, } \\
\text { and relative payoffs. }\end{array}$ & https://dl.acm.org/citation.cfm?id=2602089 \\
\hline CSRA-NPP & $\begin{array}{l}\text { Cyber Security Risk } \\
\text { Assessment in Nuclear } \\
\text { Power Plants (Korea) } \\
\end{array}$ & $\begin{array}{l}\text { Tool for identifying and characterizing risk assessment activities at } \\
\text { initial design stages }\end{array}$ & $\begin{array}{l}\text { http://koreascience.or.kr/article/ArticleFullRecord.jsp? } \\
\underline{\text { cn=OJRHBJ_2012_v44n8_919 }}\end{array}$ \\
\hline Cy-T SCADA RF & $\begin{array}{l}\text { Cyber-Terrorism SCADA } \\
\text { Risk Framework (Australia) }\end{array}$ & Measuring cyber-terrorism threats and implementing control measures & $\begin{array}{l}\text { http://ro.ecu.edu.au/cgi/viewcontent.cgi? article }=1004 \\
\text { \&context }=\text { isw }\end{array}$ \\
\hline DECRIS & $\begin{array}{l}\text { Risk and Decision Systems } \\
\text { for Critical Infrastructures }\end{array}$ & $\begin{array}{l}\text { Used for risk and vulnerability analyses that focus on critical } \\
\text { infrastructure (drinking water, energy supply, transportation, ICT) } \\
\text { interdependencies. }\end{array}$ & https://www.sintef.no/projectweb/samrisk/decris/ \\
\hline DEW & $\begin{array}{l}\text { Distributed engineering } \\
\text { workstation (Electrical } \\
\text { Distribution Design, Inc. } \\
\text { Sponsored by DOE and } \\
\text { DoD) }\end{array}$ & $\begin{array}{l}\text { Tool for identification and analysis of interdependencies, asset } \\
\text { management, and operations planning for power systems. }\end{array}$ & https://www.eee.hku.hk/ cees/software/dew.htm \\
\hline $\begin{array}{l}\text { DMRIM-SCADA } \\
\text { System }\end{array}$ & $\begin{array}{l}\text { Digraph Model for Risk } \\
\text { Identification and } \\
\text { Management in SCADA } \\
\text { System (USA). }\end{array}$ & $\begin{array}{l}\text { Tool for vulnerability identification, faults and failure diagnosis, and } \\
\text { risk impact assessment. }\end{array}$ & https://ieeexplore.ieee.org/document/5983990/ \\
\hline DUTCH NRA & Dutch Government & $\begin{array}{l}\text { Tool used for analyzing threats and hazards using multi-criteria } \\
\text { decision making techniques to achieve reduction of risks. }\end{array}$ & $\begin{array}{l}\text { https://english.nctv.nl/binaries/poster-st-geneva-2015- } \\
\text { analyst-network-(8) tcm32-84227.pdf }\end{array}$ \\
\hline EAR-PILAR & $\begin{array}{l}\text { National Cryptology Centre } \\
\text { Spain }\end{array}$ & $\begin{array}{l}\text { A tool for asset characterization, risk (threats, vulnerabilities, and } \\
\text { impacts) modelling, and control evaluations. Considers identification, } \\
\text { classification, ratings, and dependencies amongst assets }\end{array}$ & $\begin{array}{l}\text { http://www.pilar- } \\
\text { tools.com/en/tools/pilar/v7l/index.html }\end{array}$ \\
\hline ECI-GIS & $\begin{array}{l}\text { Geographic information } \\
\text { systems and risk assessment } \\
\text { (EU sponsored Joint } \\
\text { Research Centre). }\end{array}$ & $\begin{array}{l}\text { A tool for modelling operational continuity following loss and damage } \\
\text { of critical infrastructures. }\end{array}$ & https://core.ac.uk/download/pdf/38613171.pdf \\
\hline EMCAS & $\begin{array}{l}\text { Electricity Market Complex } \\
\text { Adaptive System }\end{array}$ & $\begin{array}{l}\text { Used for modelling and evaluating operational and economic impacts } \\
\text { of various external events on complex power systems (e.g. electricity) }\end{array}$ & https://www.energyplan.eu/othertools/national/emcas/ \\
\hline EpiSimS & Epidemic Simulations & Used for modeling and analysis of the spread of diseases & http://public.lanl.gov/sdelvall/p556-mniszewski.pdf \\
\hline EPRAM & $\begin{array}{l}\text { Electric Restoration } \\
\text { Analysis Tools }\end{array}$ & Used for modelling electric power restoration & http://www.mssanz.org.au/modsim2013/D2/stamber.pd \\
\hline $\begin{array}{l}\text { ERC-SCADA } \\
\text { System-Petri Net } \\
\text { Analysis }\end{array}$ & $\begin{array}{l}\text { Evaluating the Risk of } \\
\text { Cyber Attacks on SCADA } \\
\text { Systems via Petri Net } \\
\text { Analysis. }\end{array}$ & $\begin{array}{l}\text { Tool for evaluating operational risks using non-probabilistic metrics } \\
\text { approach. }\end{array}$ & https://ieeexplore.ieee.org/document/5168093/ \\
\hline EURACOM & $\begin{array}{l}\text { European Risk Assessment } \\
\text { and Contingency Planning } \\
\text { Methodologies for } \\
\text { Interconnected Energy } \\
\text { Networks }\end{array}$ & All-hazard risk assessment and contingency scheduling. & http://www.dis.anl.gov/projects/ri.html \\
\hline FAIT & $\begin{array}{l}\text { Fast Analysis Infrastructure } \\
\text { Tool (Sandia National Lab, } \\
\text { sponsored by US DHS) }\end{array}$ & $\begin{array}{l}\text { Knowledge base tool (including emergency network and } \\
\text { georeferencing data) for performing economic impact analysis across } \\
\text { multiple critical infrastructure sectors. }\end{array}$ & http://www.dis.anl.gov/projects/ri.html \\
\hline FastTrans & Los Alamos National Lab & $\begin{array}{l}\text { A parallel microsimulator tool for transportation networks for } \\
\text { simulating and routing very large numbers of vehicles on real-world } \\
\text { road networks in a fraction of real time. }\end{array}$ & $\begin{array}{l}\text { https://www.lanl.gov/orgs/adtsc/publications/science } h \\
\text { ighlights_2011/docs/6InfoSciPDFs/sunil.pdf }\end{array}$ \\
\hline FEPVA & $\begin{array}{l}\text { Framework for Electricity } \\
\text { Production Vulnerability } \\
\text { Assessment (Los Alamos } \\
\text { National Lab) }\end{array}$ & $\begin{array}{l}\text { Tool for assessing the potential impact of natural disasters or malicious } \\
\text { attacks for both response and preventative purposes. Specifically used } \\
\text { to determine the power plants with impact potentials and the extent } \\
\text { feasible. }\end{array}$ & 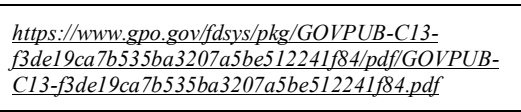 \\
\hline FINSIM & $\begin{array}{l}\text { Financial System } \\
\text { Infrastructure (Los Alamos } \\
\text { National Lab) }\end{array}$ & $\begin{array}{l}\text { Tool for modelling financial service sector as a complex decentralized } \\
\text { system with multiple interacting autonomous decision nodes or agents } \\
\text { such as banks, traders, markets, and brokers. }\end{array}$ & https://cnls.lanl.gov/annual26/abstracts.html \\
\hline FMEA/FMECA & $\begin{array}{l}\text { Failure Mode Effect and } \\
\text { Criticality analysis }\end{array}$ & $\begin{array}{l}\text { Technique for analyzing probable system failures, enumerating } \\
\text { potential impacts, and classifying control and mitigation actions. }\end{array}$ & $\begin{array}{l}\text { https://pdfs.semanticscholar.org/aba3/1bf32898f29ea5 } \\
\text { 6be2elf5b4f99938face35.pdf }\end{array}$ \\
\hline Fort Future & $\begin{array}{l}\text { US Army Corps of } \\
\text { Engineers }\end{array}$ & $\begin{array}{l}\text { A tool that follows a multiple simulation approach for multi-criteria } \\
\text { decision support. Used for simulating test plans for Department of } \\
\text { Defense installations, and evaluating a set of alternatives. }\end{array}$ & $\begin{array}{l}\underline{\text { https://ascelibrary.org/doi/pdf/10.1061/40794\%28179 }} \\
\underline{02922}\end{array}$ \\
\hline FTA & Fault Tree Analysis & $\begin{array}{l}\text { A deductive technique for evaluating risk causes from a combination of } \\
\text { inputs. }\end{array}$ & $\begin{array}{l}\text { http://asq.org/quality-progress/2002/03/problem- } \\
\text { solving/what-is-a-fault-tree-analysis.html }\end{array}$ \\
\hline $\begin{array}{l}\text { GAMS-CERO } \\
\text { ERA }\end{array}$ & Enterprise Risk Assessment & $\begin{array}{l}\text { Technique for managing and mitigating risk using administrative } \\
\text { procedures and resources. }\end{array}$ & $\underline{\text { http://www.dis.anl.gov/projects/ri.html }}$ \\
\hline GIS Interoperability & $\begin{array}{l}\text { Geographical Information } \\
\text { Systems Interoperability }\end{array}$ & $\begin{array}{l}\text { A methodology for emergency coordination and support using } \\
\text { geographical information systems. }\end{array}$ & 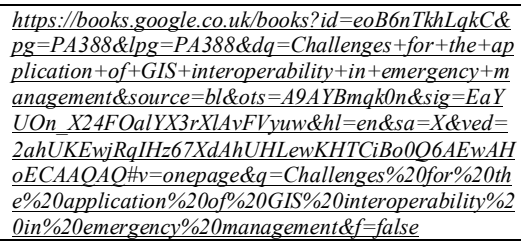 \\
\hline GoRAF & $\begin{array}{l}\text { University of New } \\
\text { Brunswick (Canada) }\end{array}$ & $\begin{array}{l}\text { A tool for critical infrastructure resource identification, and metric- } \\
\text { based estimation of economic losses. }\end{array}$ & $\begin{array}{l}\text { https://www.inderscienceonline.com/doi/pdf/10.1504/IJ } \\
\text { RAM.2007.015297 }\end{array}$ \\
\hline HAZOP & $\begin{array}{l}\text { Hazard and Operability } \\
\text { Analysis }\end{array}$ & $\begin{array}{l}\text { Technique for system examination and risk management based on } \\
\text { theory of assumptions that risk events occur due to deviations from } \\
\text { design and operating plans. }\end{array}$ & $\begin{array}{l}\text { http://pqri.org/wp- } \\
\text { content/uploads/2015/08/pdf/HAZOP_Training_Guide. } \\
\text { pdf }\end{array}$ \\
\hline HCSim & $\begin{array}{l}\text { Healthcare Simulation (Los } \\
\text { Alamos National Lab) }\end{array}$ & $\begin{array}{l}\text { A modelling tool for assessing the impact of mass casualties in health } \\
\text { care and public health institutions (e.g., hospitals) }\end{array}$ & $\begin{array}{l}\text { https://permalink.lanl.gov/object/tr? what }=\text { info:lanl- } \\
\text { repo/lareport/LA-UR-13-24605 }\end{array}$ \\
\hline
\end{tabular}


To be published in PETRAS/IET Conference Living in the Internet of Things: Cybersecurity of the IOT - 2019

\begin{tabular}{|c|c|c|c|}
\hline CIP Approaches & Full Meaning & Purpose Description & Web Link \\
\hline HM-BRMCI & $\begin{array}{l}\text { Hierarchical, model-based } \\
\text { risk Management of Critical } \\
\text { Infrastructures }\end{array}$ & $\begin{array}{l}\text { Tool for automating the definition of risk mitigation plans and } \\
\text { activities. }\end{array}$ & $\begin{array}{l}\text { https://www.sciencedirect.com/science/article/pii/S095 } \\
\underline{1832009000349}\end{array}$ \\
\hline HURT & $\begin{array}{l}\text { Hurricane Re-location Tool } \\
\text { (Los Alamos National Lab) }\end{array}$ & A tool for modelling the relocation of Hurricane & $\underline{\text { http://www.lanl.gov }}$ \\
\hline $\begin{array}{l}\text { HYDRA Pop \& } \\
\text { Eco Modeling }\end{array}$ & (Los Alamos National Lab) & $\begin{array}{l}\text { Integrated service-oriented architevture tool for modeling and } \\
\text { simulating infrastructures with seamless interoperability. }\end{array}$ & https://public.lanl.gov/rbent/hydra-with-cover.pdf \\
\hline I2SIM & $\begin{array}{l}\text { Infrastructures } \\
\text { Interdependencies } \\
\text { Simulation (University of } \\
\text { British Columbia) }\end{array}$ & $\begin{array}{l}\text { A tool for simulating scenarios for disaster responses at system level } \\
\text { with impact characterization. }\end{array}$ & http://www.ece.ubc.ca/\%7Ejiirp/ \\
\hline ICS-CDTP & $\begin{array}{l}\text { Industrial Control System } \\
\text { Cyber Defense Triage } \\
\text { Process }\end{array}$ & $\begin{array}{l}\text { Tool for threat analysis, attack modelling, and control and } \\
\text { countermeasure applications }\end{array}$ & $\begin{array}{l}\text { https://www.sciencedirect.com/science/article/pii/S016 } \\
\underline{7404817301505}\end{array}$ \\
\hline IEISS & $\begin{array}{l}\text { Interdependent } \\
\text { Environment for Infra- } \\
\text { structure System } \\
\text { Simulations (University of } \\
\text { Virginia) }\end{array}$ & $\begin{array}{l}\text { A modelling tool for simulating electricity and natural gas flow, outage } \\
\text { characteristics, and system interdependencies. }\end{array}$ & http://www.bwbush.io/projects/ieiss.html \\
\hline IIM & $\begin{array}{l}\text { Inoperability In-put-Output } \\
\text { Model (Sandia National } \\
\text { Labs and Los Alamos } \\
\text { National Labs) } \\
\end{array}$ & $\begin{array}{l}\text { A tool for sector-based economic impact analysis of infrastructure } \\
\text { attacks and failures. }\end{array}$ & $\begin{array}{l}\text { https://ascelibrary.org/doi/pdf/10.1061/\%28ASCE\%29 } \\
\underline{1076-0342 \% 282005 \% 2911 \% 3 A 2 \% 2867 \% 29}\end{array}$ \\
\hline $\begin{array}{l}\text { Infrastructure } \\
\text { Disruptions }\end{array}$ & - & $\begin{array}{l}\text { Tool for modelling the state of infrastructure systems under abnormal } \\
\text { conditions, and evaluating the economic consequences of } \\
\text { abnormalities. }\end{array}$ & http://www.dis.anl.gov/projects/ri.html \\
\hline INTEPOINT VU & IntePoint LLC & $\begin{array}{l}\text { A modelling tool that combines various techniques for complex } \\
\text { environments analysis and system-wide interdependencies modelling } \\
\text { across physical, virtual and social networks. }\end{array}$ & $\begin{array}{l}\frac{\text { https://www.nist.gov/sites/default/files/documents/el/ms }}{\text { id/Critical_Infrastructure.pdf }} \\
\underline{\text { nald }}\end{array}$ \\
\hline IRAM & $\begin{array}{l}\text { Infrastructure risk analysis } \\
\text { model (US Military } \\
\text { Academy) }\end{array}$ & $\begin{array}{l}\text { Tool used to model and simulate resource allocation for interconnected } \\
\text { infrastructure reliability. Used for risk quantification. }\end{array}$ & $\begin{array}{l}\text { https://ascelibrary.org/doi/10.1061/\%28ASCE\%29107 } \\
\text { 6-0342\%282000\%296\%3A3\%28114\%29 }\end{array}$ \\
\hline $\begin{array}{l}\text { IRAM-SCADA } \\
\text { INFORMATION } \\
\text { Sec }\end{array}$ & $\begin{array}{l}\text { Improved Risk Assessment } \\
\text { Method for SCADA } \\
\text { Information Security } \\
\text { (Serbia) }\end{array}$ & $\begin{array}{l}\text { Evaluating the effectiveness of intrusion, detection, and prevention } \\
\text { systems in controlling attacks. }\end{array}$ & $\underline{\underline{\text { http://eejournal.ktu.lt/index.php/elt/article/view/8027/4 }}}$ \\
\hline IRRIIS & $\begin{array}{l}\text { Integrated Risk Reduction } \\
\text { of In-formation-based Infra- } \\
\text { structure Systems (IRRIIS } \\
\text { Project, EU) }\end{array}$ & $\begin{array}{l}\text { Interdependency and resilience modelling, analysis and management of } \\
\text { critical infrastructures }\end{array}$ & https://www.irriis.org \\
\hline $\begin{array}{l}\text { Knowledge Mgt \& } \\
\text { Visualisation }\end{array}$ & Carnegie Mellon University & Tool for analyzing vulnerabilities related to the distribution of fuel & https://inldigitallibrary.inl.gov/sti/3489532.pdf \\
\hline LogiSims & $\begin{array}{l}\text { Los Alamos National } \\
\text { Laboratory }\end{array}$ & $\begin{array}{l}\text { Tool for modelling and planning preparation for a disasters and } \\
\text { concurrent responses to a disaster }\end{array}$ & http://public.lanl.gov/rbent/bent-pes.pdf \\
\hline LS-DYNA & $\begin{array}{l}\text { Livermore Software } \\
\text { Technology Corporation }\end{array}$ & $\begin{array}{l}\text { A tool for modelling large complex system structures and behaviours } \\
\text { related to failures such as: changing boundary conditions, deformations, } \\
\text { crashes and explosions. }\end{array}$ & $\underline{\text { http://www.lstc.com/products/ls-dyna }}$ \\
\hline LUND & $\begin{array}{l}\text { University of Lund } \\
\text { (Sweden). Sponsored by the } \\
\text { International Energy } \\
\text { Agency }\end{array}$ & $\begin{array}{l}\text { Grounded Network theory methodology for modelling the relationships } \\
\text { between nodes in a system of roads or rail interconnected transport } \\
\text { infrastructure. }\end{array}$ & $\frac{\text { https://www.iea.lth.se/publications/Theses/LTH-IEA- }}{\underline{1061 . p d f}}$ \\
\hline MARGERIT V2 & $\begin{array}{l}\text { Spanish Ministry for Public } \\
\text { Administrations }\end{array}$ & $\begin{array}{l}\text { methodology for Risk Analysis and Management for security of } \\
\text { computer systems, digital and data networks. }\end{array}$ & $\begin{array}{l}\text { https://www.enisa.europa.eu/topics/threat-risk- } \\
\text { management/risk-management/current-risk/risk- } \\
\text { management-inventory/rm-ra-methods/m_magerit.html }\end{array}$ \\
\hline MBRA & $\begin{array}{l}\text { Model-Based Risk } \\
\text { Assessment (Naval } \\
\text { Postgraduate School, Center } \\
\text { for Homeland Defense \& } \\
\text { Security) } \\
\end{array}$ & $\begin{array}{l}\text { Analysis of critical infrastructure network components and faults for } \\
\text { efficient resource allocation }\end{array}$ & https://www.chds.us/ed/items/2164 \\
\hline MIA & $\begin{array}{l}\text { Methodology for } \\
\text { Interdependency } \\
\text { Assessment }\end{array}$ & $\begin{array}{l}\text { A methodology for identifying and characterizing critical } \\
\text { interdependencies of the systems in relations security vulnerabilities. }\end{array}$ & $\begin{array}{l}\text { https://link.springer.com/content/pdf/10.1007\%2F978- } \\
\underline{3-642-21694-7 \text { I.pdf }}\end{array}$ \\
\hline MIITS & $\begin{array}{l}\text { Multi-Scale Integrated } \\
\text { Information \& } \\
\text { Telecommunications } \\
\text { System (Los Alamos } \\
\text { National Laboratories) } \\
\end{array}$ & $\begin{array}{l}\text { A tool for simulating high fidelity network topology, internet } \\
\text { communication sessions and packets, and actual scalability } \\
\text { representations. }\end{array}$ & https://ieeexplore.ieee.org/document/4117861/ \\
\hline MIN & $\begin{array}{l}\text { Multi-layer Infrastructure } \\
\text { Networks (Purdue } \\
\text { University) }\end{array}$ & $\begin{array}{l}\text { A simulation tool for solving flow equilibrium and optimal budget } \\
\text { allocation problem related to automobile, urban freight and data } \\
\text { network layer }\end{array}$ & $\begin{array}{l}\text { https://link.springer.com/content/pdf/10.1007\%2Fs } 110 \\
\underline{67-005-2627-0 . p d f}\end{array}$ \\
\hline $\begin{array}{l}\text { Modular Dynamic } \\
\text { Model }\end{array}$ & Sandia National Laboratory & $\begin{array}{l}\text { A tool for modelling and simulating energy infrastructure } \\
\text { interdependency operations including generation, transmission, } \\
\text { distributions and trading. }\end{array}$ & $\begin{array}{l}\text { https://www.sandia.gov/nisac-ssl/wp/wp- } \\
\text { content/uploads/downloads/2012/04/a-modular- } \\
\text { dynamic-simulation-model.pdf }\end{array}$ \\
\hline MSM & $\begin{array}{l}\text { MIT Screening } \\
\text { Methodology (MIT }= \\
\text { Massachusetts Institute of } \\
\text { Technology) }\end{array}$ & A methodology for prioritizing vulnerabilities & http://www.dis.anl.gov/projects/ri.html \\
\hline MUNICIPAL & $\begin{array}{l}\text { Multi-Network } \\
\text { Interdependent Critical } \\
\text { Infrastructure Program for } \\
\text { Analysis of Lifelines } \\
\text { (Rensselaer Poly-technic } \\
\text { Institute, USA) }\end{array}$ & $\begin{array}{l}\text { A decision support tool simulating infrastructure moving parts and } \\
\text { interdependencies within coastal regions to define optimal response } \\
\text { before, during and after hazards. }\end{array}$ & $\begin{array}{l}\text { http://eaton.math.rpi.edu/faculty/Mitchell/papers/decisi } \\
\underline{\text { ontechnologies.pdf }}\end{array}$ \\
\hline N-ABLE & $\begin{array}{l}\text { National A-gent-Based } \\
\text { Laboratory for Economics } \\
\text { (Sandia National } \\
\text { Laboratories and Los } \\
\text { Alamos National } \\
\text { Laboratories) }\end{array}$ & $\begin{array}{l}\text { A tool for analyzing economic factors, responses and downstream } \\
\text { consequences of infrastructure interdependencies }\end{array}$ & http://www.dis.anl.gov/projects/ri.html \\
\hline NEMO & $\begin{array}{l}\text { Net-Centric Effects-based } \\
\text { Operations Model (Sparta, } \\
\text { Inc.) }\end{array}$ & $\begin{array}{l}\text { A tool for modelling impact cascades of events through multiple } \\
\text { infrastructure networks, and determining the results of course of } \\
\text { actions. }\end{array}$ & $\begin{array}{l}\text { http://www.dodccrp.org/events/10th_ICCRTS/CD/pape } \\
\text { rs/128.pdf }\end{array}$ \\
\hline
\end{tabular}


To be published in PETRAS/IET Conference Living in the Internet of Things: Cybersecurity of the IOT - 2019

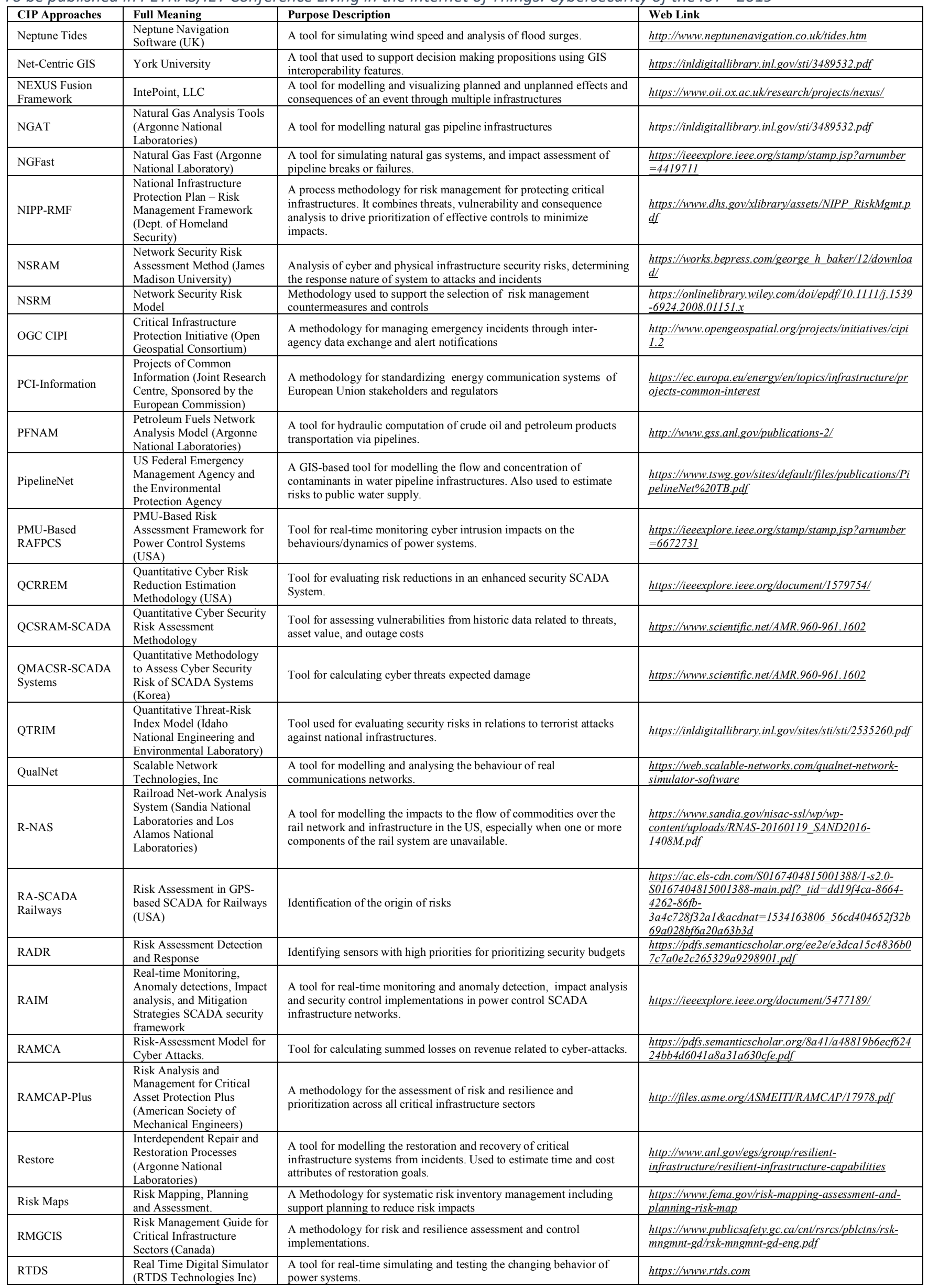


To be published in PETRAS/IET Conference Living in the Internet of Things: Cybersecurity of the IOT - 2019

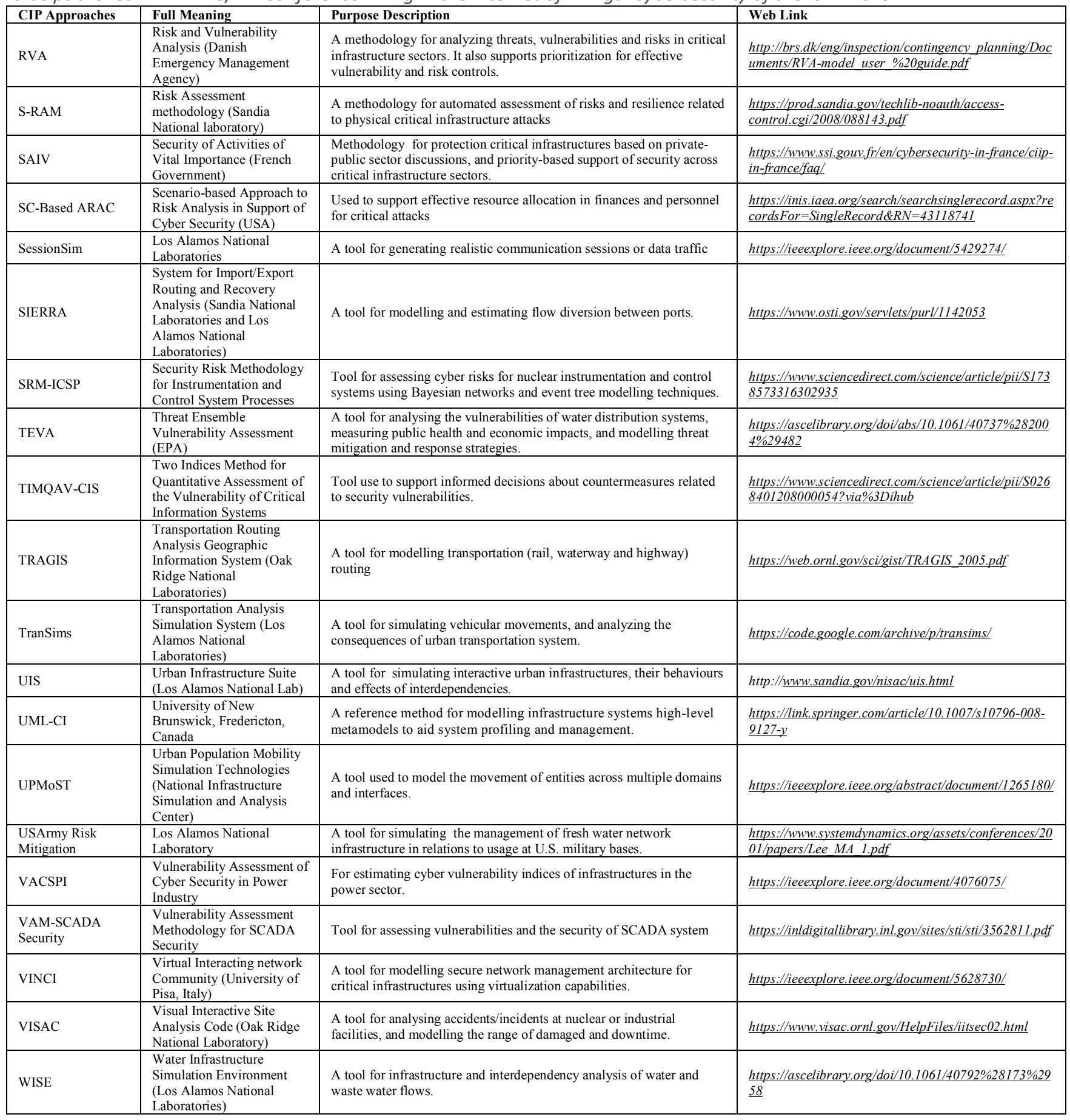

